\title{
Bottom-up processes mediated by social systems drive demographic traits of coral-reef fishes
}

\author{
Brett M. Taylor, ${ }^{1,10}$ Simon J. Brandl, ${ }^{2}$ Maia Kapur, ${ }^{1}$ William D. Robbins,${ }^{3,4,5}$ Garrett Johnson, ${ }^{6}$ \\ Charlie Huveneers, ${ }^{7}$ Phil Renaud, ${ }^{8}$ and John Howard Choat $^{9}$ \\ ${ }^{1}$ Joint Institute for Marine and Atmospheric Research, Pacific Islands Fisheries Science Center, University of Hawaii and NOAA \\ Fisheries, Honolulu, Hawaii 96818 USA \\ ${ }^{2}$ Tennenbaum Marine Observatories Network, Smithsonian Environmental Research Center, Edgewater, Maryland 21037 USA \\ ${ }^{3}$ Wildlife Marine, Perth, Western Australia 6020 Australia \\ ${ }^{4}$ Department of Environment and Agriculture, Curtin University, Perth, Western Australia 6102 Australia \\ ${ }^{5}$ School of Life Sciences, University of Technology Sydney, Sydney, New South Wales 2007 Australia \\ ${ }^{6}$ Hawaii Institute of Marine Biology, University of Hawaii, Kaneohe, Hawaii 96744 USA \\ ${ }^{7}$ College of Science and Engineering, Flinders University, Bedford Park, South Australia 5042 Australia \\ ${ }^{8}$ Khaled Bin Sultan Living Oceans Foundation, Annapolis, Maryland 21403 USA \\ ${ }^{9}$ College of Science and Engineering, James Cook University, Townsville, Queensland 4811 Australia
}

\begin{abstract}
Ectotherms exhibit considerable plasticity in their life-history traits. This plasticity can reflect variability in environmental and social factors, but the causes of observed patterns are often obscured with increasing spatial scales. We surveyed dichromatic parrotfishes across the northern Great Barrier Reef to examine variation in body size distributions and concomitant size at sex change $\left(L_{\Delta 50}\right)$ against hypotheses of directional influence from biotic and abiotic factors known to affect demography. By integrating top-down, horizontal, and bottomup processes, we demonstrate a strong association between exposure regimes (which are known to influence nutritional ecology and mating systems) and both body size distribution and $L_{\Delta 50}$ (median length at female-to-male sex change), with an accompanying lack of strong empirical support for other biotic drivers previously hypothesized to affect body size distributions. Across sites, body size was predictably linked to variation in temperature and productivity, but the strongest predictor was whether subpopulations occurred at sheltered mid and inner shelf reefs or at wave-exposed outer shelf reef systems. Upon accounting for the underlying influence of body size distribution, this habitat-exposure gradient was highly associated with further $L_{\Delta 50}$ variation across species, demonstrating that differences in mating systems across exposure gradients affect the timing of sex change beyond variation concomitant with differing overall body sizes. We posit that exposure-driven differences in habitat disturbance regimes have marked effects on the nutritional ecology of parrotfishes, leading to size-related variation in mating systems, which underpin the observed patterns. Our results call for better integration of life-history, social factors, and ecosystem processes to foster an improved understanding of complex ecosystems such as coral reefs.
\end{abstract}

Key words: life-history variation; parrotfishes; reaction norm; resource variability; sex allocation; sex change; structural equation model.

\section{INTRODUCTION}

Phenotypic traits in organisms often show considerable variability across space or time, representing adaptive responses to changes in the surrounding environment (Fagen 1987). The response capacity of a genotype to external conditions, manifested as phenotypic plasticity, allows individuals or populations to persist within a range of environments by optimizing regional fitness to maximize survival (Bradshaw 1965, Schlichting and Pigliucci 1998). The resulting patterns of phenotypic variability can be measured as reaction norms across environmental or

Manuscript received 27 July 2017; revised 7 December 2017; accepted 18 December 2017. Corresponding Editor: Mark A. Hixon.

${ }^{10}$ E-mail: brett.taylor@noaa.gov anthropogenic gradients and are observed across a variety of spatial and temporal scales (Schmalhausen 1949, Schlichting and Pigliucci 1998). A species' inherent capacity to adapt to local conditions by altering its physiological rates helps explain species-specific distributions on both regional $(10-100 \mathrm{~s} \mathrm{~km})$ and biogeographic scales $(1,000 \mathrm{~s} \mathrm{~km})$ and can facilitate predictions of population and ecosystem dynamics under changing environmental conditions (Munday et al. 2008). Life-history traits, such as growth rate or age at maturity, are the embodiment of physiological processes in organisms. Understanding how and why such traits vary provides a link between ecological and evolutionary mechanisms, their response to prevailing biotic and environmental conditions, and biogeochemical pathways within ecosystems (Warner 1991, Agrawal 2001, Hutchings 2011). Thus, examination of trait variability can provide a powerful path to 
understanding spatio-temporal variation in fundamental ecosystem processes.

Sex allocation theory (Charnov 1982) provides a framework for understanding the advantage of resource distribution among males and females in a population. Stemming from this framework, the size-advantage hypothesis (Ghiselin 1969) predicts that protogynous hermaphroditism will be favored when size-mediated reproductive value increases at a greater rate in males than females (Warner 1975), with the male-female intercept of reproductive value representing the optimal size at which to change sex in a population. Hence, within a species, variability in the size of sex change is strongly linked to extant body size distributions (Allsop and West 2003, Gardner et al. 2005), but is also influenced by social factors such as mating system. Features of the surrounding environment can affect population dynamics within a species, leading to alternative mating behaviors across space (Henson and Warner 1997). These alternative mating behaviors, such as territorial haremic behaviors vs. group spawning, can modify the reproductive values of males and females across size or age classes within a species (Warner 1975), thus influencing the timing of sex change or even the decision of whether to change sex. However, because of the interrelated nature of life-history processes, teasing apart the factors regulating such processes is challenging (Schaffer 2004). Accomplishing this in a holistic manner requires a study system spanning a spatial scale encompassing a broad spectrum of environmental variability.

Coral reefs represent one of the most diverse and dynamic ecosystems on Earth. Coral reef fishes are known to display a wide range of social and reproductive systems and are subject to a multitude of environmental and biological factors, including small-scale variability in water quality, wave exposure, ambient temperature, habitat complexity, resource availability, competitive interactions, and lethal and sub-lethal effects of predation (Sale 2002, Mora 2015). A substantial body of literature suggests that these factors yield adaptive responses in life-history traits such as growth rate, body size, mortality, life span, and reproductive dynamics (Warner and Hoffman 1980, Robertson et al. 2005, Ruttenberg et al. 2005, Munday et al. 2006, Taylor 2014). To date, one of the most conspicuous and consistent patterns of variation in life-history traits has been observed over small scales $(\leq 20 \mathrm{~km})$ between sheltered and exposed reefs on a longitudinal gradient (Gust et al. 2002, Gust 2004). This pattern revealed higher mortality, smaller size-atage, shorter life spans, earlier reproductive development, and greater proportions of initial phase primary males (a male alternative reproductive behavior determined prematurationally and with implications to the mating system) on exposed outer shelf reefs vs. the sheltered mid shelf reefs, and this outcome was linked to differences in competition and predation. These patterns provided a rationale for identifying biotic top-down and horizontal processes as primary drivers of demographic variation (Gust et al. 2002). However, reef ecosystems are also subject to markedly different environmental conditions at large spatial scales. This variation is reflected in differing patterns of reef configuration, hydrodynamics, or history and frequency of disturbance, and is especially relevant to reef systems that span latitudinal gradients sufficient to reflect changes in sea surface temperature. Yet, the relative extent to which biological factors are pertinent drivers of demography over a gradient extensive enough to reflect geographic-scale environmental variation is unknown.

Scaling up analyses of life-history features to allow investigation over an appropriate geographic scale is important to investigate the extent to which small- and broad-scale processes contribute to the demographic patterns we find today. We examine drivers of trait variability using a multi-scale design across $6^{\circ}$ of latitude spanning the northern half of the Australian Great Barrier Reef (GBR). This system includes significant environmental variation on both longitudinal (wave exposure gradient of 40-100 km) and latitudinal $(\leq 1,000 \mathrm{~km})$ axes. In recognizing that various environmental and biotic factors in complex natural systems are interdependent and hierarchically structured, we use a structural equation modelling framework to test hypothesized pathways that yield striking differences in body size distributions observed between shelf environments. We then focus on variability in the relationship between body size and length of female-to-male sex change in parrotfishes, traits that are heavily linked to physiological processes of growth and maturity, as well as with social demography and surrounding environment (Shapiro 1991). By examining covariance among environmental gradients and reaction norms of trait variability, the present study represents the first rigorous holistic test of multiple, hierarchical drivers of life-history variation in reef fishes in the absence of direct human exploitation on the study species.

\section{Methods}

We surveyed 82 sites within 31 reefs along $6^{\circ}$ of latitude on the northern GBR, Australia (Fig. 1A), where parrotfishes are not exploited by humans. Surveys were conducted during Sep-Oct 2014, using diver-operated stereo-video along 40-min timed swims ( $5 \mathrm{~m}$ wide), with a towed GPS on a surface buoy showing an average speed of $20.3 \mathrm{~m} / \mathrm{min}( \pm 3.98 \mathrm{~m} / \mathrm{min} \mathrm{SD})$. Surveys were conducted on the outer reef slopes at 6-10 m depth and were stratified across two shelf positions (exposed and sheltered) and three management zones (no entry, no fishing, and fishing allowed; Appendix S1: Table S1). All surveys were conducted on seaward (east-facing) reef slopes of sheltered (inner and mid shelf) and exposed (outer shelf) reefs. Parrotfish surveyed by stereo-video were measured to the nearest $\mathrm{mm}$ fork length and recorded by color phase (initial or terminal phase) using the EventMeasure software (seagis.com.au). A second diver visually surveyed all sharks, carangids, and other 

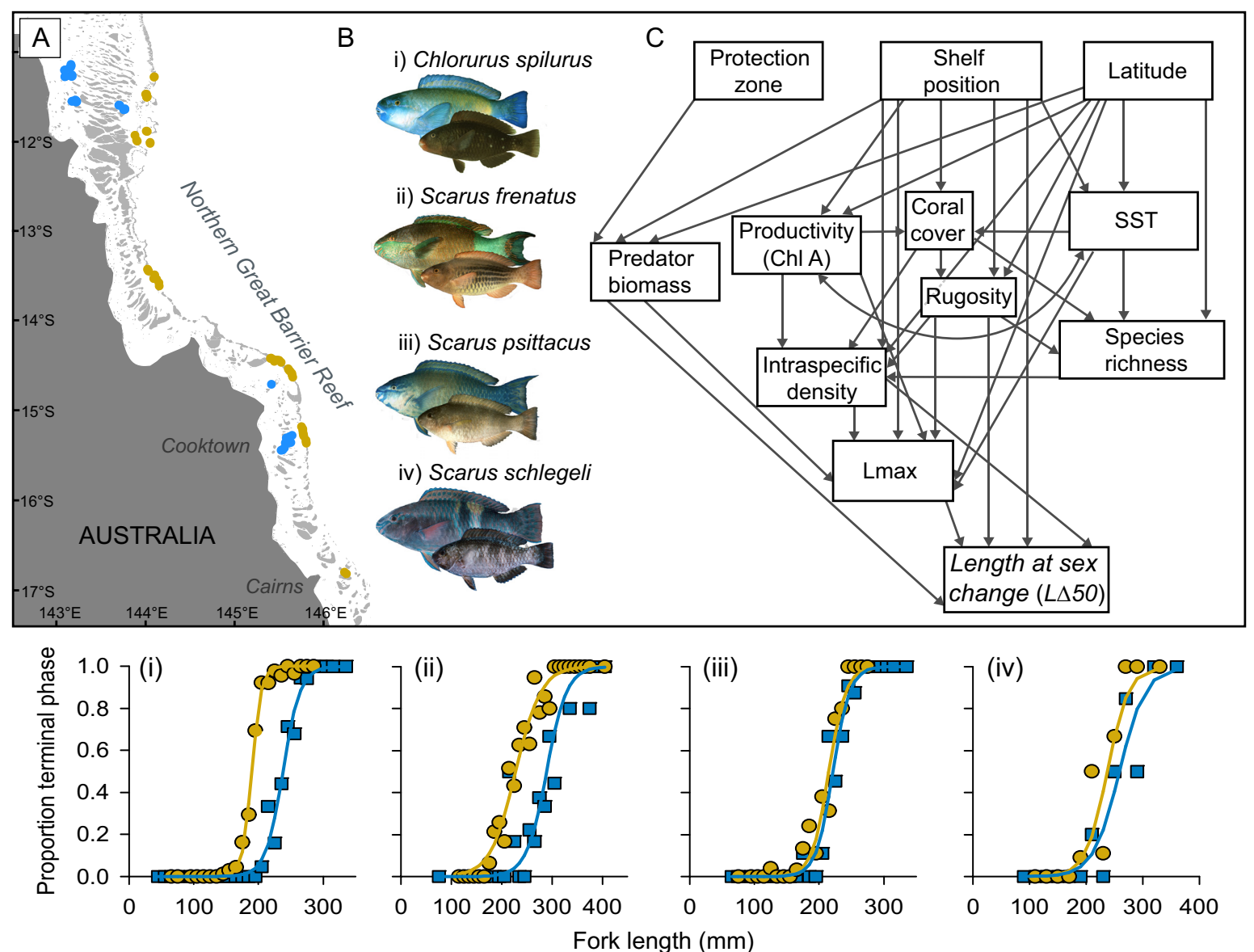

FIG. 1. (A) Map of 82 sites across the northern Great Barrier Reef. Exposed sites in yellow, sheltered sites in blue. (B) Species with associated color phases of initial (lower, front) and terminal (above, behind) broadly representing females and males, respectively. (C) Hypothesized pathways of influence from exogenous to endogenous biotic and abiotic factors ultimately affecting maximum length and length at sex change. Curved, double-headed arrows indicate correlated error structure. (i-iv) Comparison of sex change schedules for species in (B) pooled across exposed (yellow) and sheltered (blue) sites. Confidence ellipses surrounding $L_{\Delta 50}$ and $L_{\Delta 95}$ estimates are displayed in Appendix S1: Fig. S1.

large mobile piscivores along a wider transect $(20 \mathrm{~m}$ wide), and lengths and abundances of smaller predators were determined from video analysis.

We estimated the median length at female-to-male sex change $\left(L_{\Delta 50}\right)$ by site of the four most common parrotfish species with dichromatic coloration on video surveys (Chlorurus spilurus, Scarus frenatus, S. psittacus, and S. schlegeli) at both exposed and sheltered habitats (Fig. 1B). Either a logistic model (see Data Analysis section) fitted to relative proportions of initial and terminal phase individuals across the various length classes, or the midpoint between the largest initial phase and smallest terminal phase individual (when lengths of color phases did not overlap) was used to estimate $L_{\Delta 50}$ by species and site. The use of color phase is a highly robust proxy for estimating functional sex change in parrotfishes, and the potentially confounding presence of initial phase primary males has a minor effect on $L_{\Delta 50}$ estimates (Taylor 2014). We further estimated a proxy to represent the high-range of the length frequency distribution for each species by site using the 95th quantile of length $\left(L_{\max }\right)$. This approach provided a "buffered" estimate of maximum length because actual observed maximum length can vary by breadth of exposure to the population.

\section{Environmental data}

We measured a range of environmental factors known or hypothesized to influence life-history variation either directly or indirectly (Appendix S1: Table S2). Speciesspecific densities (individuals/ha) were estimated from standardized video surveys and represented the intensity of intraspecific competition. Species richness was treated as the total number of parrotfish species observed at a site and was highly correlated with more complex diversity measures. Predator biomass (as a proxy for the prevailing level of predation) represented the mean biomass density of all species (using appropriate size classes) known or highly suspected to prey upon parrotfish species based on 
an exhaustive literature search regarding diets and lengthweight ratios of piscivores surveyed. Reef area (in hectares), reef slope $\left(0-90^{\circ}\right.$; mean of ten measurements per site from random video frames), habitat rugosity, and coral cover (1-5 scale; mean of ten estimates per site from random video frames) were measured to represent potential features of the environment influencing carrying capacity or spawning dynamics across reefs. Metabolic rates of ectothermic primary consumers are also influenced by sea surface temperature (SST) and primary production; hence, we acquired remotely sensed SST as well as chlorophyll-A (Chl-A) data as a proxy for benthic productivity (Appendix S1: Table S2). Importantly, while satellite-derived SST can be a high-quality reflection of ambient SST (Kilpatrick et al. 2015), the relationship between satellite-derived pelagic Chl-A and benthic productivity can be highly tenuous (Gove et al. 2013), especially for complex ecosystems such as the GBR. However, the relative differences in estimated productivity values across regions and shelf positions were broadly similar to those of in-situ measurements of chlorophyll sampling stations across geographically comparable locations of the GBR (Brodie et al. 2007). Nevertheless, with such a coarse measure of primary productivity, the relative effects here should be interpreted with caution.

A primary determinant of sex change dynamics is the prevailing type of mating system. While it was not feasible to collect empirical data on mating systems across the scale of the study, Gust (2004) found pronounced differences in the reproductive biology of C. spilurus populations, implying sheltered populations had almost exclusively haremic territorial systems, whereas territoriality was less pronounced (suggesting increased rates of group spawning) at exposed outer shelf reefs. In the absence of this information for our sites, we used shelf position to represent variation in exposure as well as a proxy for concomitant differences in mating systems, as it relates to timing of sex change.

\section{Data analysis}

We first examined the consistency and ubiquity of trends in $L_{\Delta 50}$ across exposure levels. Relative proportions of initial and terminal phase individuals across length classes were pooled by exposure regimes and fitted with logistic models for each species following $P_{L}=\left\{1+e^{-\ln (19)\left(L-L_{\Delta 50}\right) /\left(L_{\Delta 95}-L_{\Delta 50}\right)}\right\}^{-1}$, where $P_{\mathrm{L}}$ is the estimated proportion of terminal phase individuals at a given length $(L), 19$ represents the number of breakpoints to the 95 th quantile in a cumulative density function $(19 / 20=0.95 ;$ Haddon 2001$)$, and $L_{\Delta 50}$ and $L_{\Delta 95}$ are the length at $50 \%$ and $95 \%$ sex change, respectively. We generated corresponding 95\% confidence ellipses surrounding $L_{\Delta 50}$ and $L_{\Delta 95}$ estimates for comparison by bootstrap resampling through 1,000 iterations.

We then devised an integrated set of hypotheses to explain patterns in $L_{\max }$ (penultimate response variable) and $L_{\Delta 50}$ (ultimate response variable) across all sites surveyed in the study (Fig. 1C). We included three exogenous variables (Shelf position [ordinal; $0=$ sheltered, 1 = exposed], Protection zone [ordinal; 0 = fishing allowed, $1=$ no fishing zone, $2=$ no-entry zone)], and Latitude [absolute degrees latitude South]) and nine endogenous variables (Sea Surface Temperature [SST], Productivity [Chl-A], Coral cover, Rugosity, Predator biomass, Intraspecific density, Species richness [of parrotfish], $L_{\max }$, and $L_{\Delta 50}$ ). Habitat variables Coral cover, Rugosity, Reef area, and Slope were assessed independently before full model construction and non-significant variables Reef area and Slope were eliminated to avoid over-parameterization of the resultant models and to improve clarity of the path diagram. We analyzed all specified paths as linked equations using a structural equation modeling approach (SEM) based on d-separation tests (Shipley 2009), which permits the rigorous quantification of indirect effects in a causal network and provides an overall goodness-of-fit measure for an a priori model through the statistical evaluation of a series of independence claims. Given the hierarchical nature of our data, we used a piecewise SEM approach (Lefcheck 2015), which allows the specification of models that can accommodate random effects. We formulated the following linkages: (1) Productivity and SST are affected by Shelf position and Latitude and are subject to unquantified common sources of variation (requiring the inclusion of a correlated error structure between Productivity and SST); (2) Coral cover is affected by Shelf position, Productivity, and SST; (3) Rugosity is affected by Shelf position, Coral cover, and Latitude; (4) Predator biomass is affected by Protection zone, Latitude, and Shelf position; (5) Species richness is affected by Coral cover, Rugosity, Latitude, and SST; (6) Intraspecific density is affected by Productivity, Species richness, Latitude, Coral cover, Rugosity, and Shelf position; (7) $L_{\max }$ is affected by Shelf Position, Latitude, SST, Productivity, Intraspecific density, Rugosity, and Predator biomass; and (8) $L_{\Delta 50}$ is affected by Shelf position (interpreted here as alternative mating systems), $L_{\max }$, Predator biomass, Intraspecific density, and Rugosity. For models (1) through (5), a random intercept was specified for each surveyed reef. For models (6), (7), and (8) (which included species-specific estimates of density, $L_{\max }$, and $L_{\Delta 50}$ ), the random intercept for reefs was nested within species. Estimates of $L_{\max }$ and $L_{\Delta 50}$ for all species were scaled and centered prior to the analyses to eliminate biases linked to differences in body size among species, while Latitude, SST, Predator biomass, Species richness, and Intraspecific density were log-transformed to satisfy assumptions of normality and homogeneity of variance. The goodness-of-fit of the devised model was evaluated using Fisher's C statistic on the cumulative results of the d-separation tests (Shipley 2009). Model coefficients were standardized by their mean and variance to facilitate comparison. For all significant pathways (and all pathways leading into $L_{\max }$ and $L_{\Delta 50}$ ), we visualized relationships using partial regression plots. In addition, goodness-of-fit values $\left(R^{2}\right)$ were extracted for 
each component model. Homogeneity of variance was visually verified for each component model using residual plots. All analyses were performed using R version 3.2.3.

\section{Results}

Across 82 sites spanning the northern GBR, the median fork length at sex change $\left(L_{\Delta 50}\right)$ ranged from 165 to $266 \mathrm{~mm}$ for $C$. spilurus, 181 to $313 \mathrm{~mm}$ for $S$. frenatus, 166 to $245 \mathrm{~mm}$ for $S$. psittacus, and 156 to $332 \mathrm{~mm}$ for S. schlegeli. All four species had larger collective $L_{\Delta 50}$ values at sheltered vs. exposed reefs (Fig. 1). This difference was highly pronounced for $C$. spilurus and $S$. frenatus, resulting in non-overlapping $95 \%$ confidence ellipses surrounding sex change parameters, while a similar suggestive trend for $S$. psittacus and $S$. schlegeli was present (Appendix S1; Fig. S1).

In the structural equation model (SEM), Shelf position, Latitude, SST, Rugosity, and Productivity exhibited significant effects on $L_{\max }$ (Fig. 2; Appendix S1: Fig. S2), with more sheltered reefs, lower Latitude, lower SST, lower Rugosity, and higher Productivity associated with larger body size distributions (standardized parameter estimate: Exposed $=-1.212 \pm 0.184$ SE; $P<0.0001 ; \quad$ Fig. 2I; Latitude $=-0.365 \pm 0.118$ SE; $P=0.0029 ; \quad$ Fig. 2J; $S S T=-0.315 \pm 0.123$ SE; $P=0.0126 ;$ Rugosity $=$ $-0.0172 \pm 0.072 \quad$ SE; $\quad P=0.0189 ; \quad$ Productivity $=$ $0.169 \pm 0.075 \mathrm{SE} ; P=0.0271)$. The negative relationship between $L_{\max }$ and Latitude was unpredicted, but appears to be an artefact of the spatial distribution of sheltered and exposed sites in our survey. In contrast, Intraspecific density and Predator biomass had no effect on $L_{\max }$. As predicted, $L_{\Delta 50}$ was significantly and positively associated with $L_{\max }\left(L_{\max }=0.392 \pm 0.065 \mathrm{SE} ; P<0.0001\right.$; Fig. 2K), but was most strongly associated with Shelf position (Exposed $=-0.875 \pm 0.156 ; P<0.0001 ;$ Fig. 2L). This result suggests that a large portion of the influence of Shelf position on $L_{\Delta 50}$ was not transferred through shelfassociated differences in body size distribution, but instead directly and independently related to shelf-associated alternative mating systems. No other factors included in the model significantly affected estimates of $L_{\Delta 50}$ across sites (Appendix S1: Fig. S2). The marginal model fit for the $L_{\max }$-model was 0.352 (marginal $R^{2}$ ), while the conditional model fit was 0.556 (conditional $R^{2}$ ). For the $L_{\Delta 50}$-model, these values were 0.522 (marginal $R^{2}$ ) and 0.556 (conditional $R^{2}$ ). Other significant pathways in the model included an effect of Shelf position and Latitude on SST (Exposed $=-0.608 \pm 0.255$ SE; $P=0.0241$; Latitude $=-0.709 \pm 0.118 \quad$ SE; $\quad P<0.0001 ; \quad$ Fig. 2A; Appendix S1: Fig. S2), an effect of Protection zone, Shelf position, and Latitude on Predator biomass (Noentry $=0.559 \pm 0.140 \quad \mathrm{SE} ; \quad P=0.0001 ; \quad$ Exposed $=$ $0.824 \pm 0.171 \quad \mathrm{SE} ; \quad P=0.0001 ; \quad$ Latitude $=-0.166 \pm$ 0.078 SE; $P=0.0348$; Fig. 2B,C; Appendix S1: Fig. S2), an effect of Species richness and Latitude on Intraspecific density (Species richness $=0.218 \pm 0.068$ SE; $P=0.0022$;
Latitude $=0.293 \pm 0.091 \mathrm{SE} ; P=0.0020$; Fig. 2D,E), an effect of SST and Shelf position on Coral cover (SST = $0.384 \pm 0.147 \mathrm{SE} ; P=0.0102 ;$ Exposed $=0.738 \pm 0.347$ SE; $P=0.0426$; Appendix S1: Fig. S2), an effect of Coral cover, Latitude, and Shelf position on Rugosity (Coral cover $=0.631 \pm 0.080 \mathrm{SE} ; P<0.0001 ;$ Latitude $=$ $0.527 \pm 0.095$ SE; $P<0.0001 ; \quad$ Exposed $=-0.978 \pm$ 0.200 SE; $P<0.0001$; Fig. $2 \mathrm{~F}-\mathrm{H}$ ), and contrasting effects of Coral cover and Rugosity on Species richness (Coral cover $=0.203 \pm 0.100 \quad \mathrm{SE} ; \quad P=0.0455 ; \quad$ Rugosity $=$ $-0.173 \pm 0.082 \mathrm{SE} ; P=0.0367$; Appendix S1: Fig. S2).

Overall, results of the SEM supported the a priori specified pathways. Specifically, Fisher's C statistic revealed that $P$-values obtained through d-separation tests of independence claims were likely to occur by chance $(C=63.93, d f=54, P=0.167)$, suggesting no important pathways among the specified variables were omitted from the hypothesized model. Summaries of the coefficients and component model fits are provided in Appendix S1: Tables S3-S4.

The interplay between Shelf position, $L_{\max }$, and $L_{\Delta 50}$ is visualized in Fig. 3. Linear regressions between $L_{\max }$ and $L_{\Delta 50}$ demonstrate, as predicted, a positive relationship between these factors. However, the residuals of this relationship are separated by Shelf position for all four species, whereby sex change occurs on average at larger than expected body sizes (relative to underlying body size distributions) at sheltered sites. This pattern was highly pronounced for C. spilurus and S. frenatus, but less conclusive for the more data-limited species $S$. psittacus and S. schlegeli.

\section{Discussion}

Despite a number of causal links between shelf position and biophysical factors, our results demonstrate the overwhelming significance and generality of shelf position mediating parrotfish body size and associated length at sex change. This conclusion is accompanied by a lack of direct support for the roles of some previously hypothesized biotic interactions, specifically predator-induced mortality estimated as predator biomass (DeMartini et al. 2005, 2008, Hall and Kingsford 2016) and intraspecific competition estimated as density (Gust 2004), in driving variation in body size distributions. The timing of sex change is heavily influenced by features of the social system (Ross 1990), and our results demonstrate that length at sex change is linked to local size distribution. However, for at least two of our study species, an additional directional response in $L_{\Delta 50}$ beyond that explained by underlying size distributions was linked with a common source of variation associated with exposure regime alone, presumably consistent with alternative mating systems between shelf positions. Below, we frame our interpretations of these observed spatial patterns of trait variation in light of nutritional ecology, sex allocation theory, and mating systems across complex and variable ecosystems. 

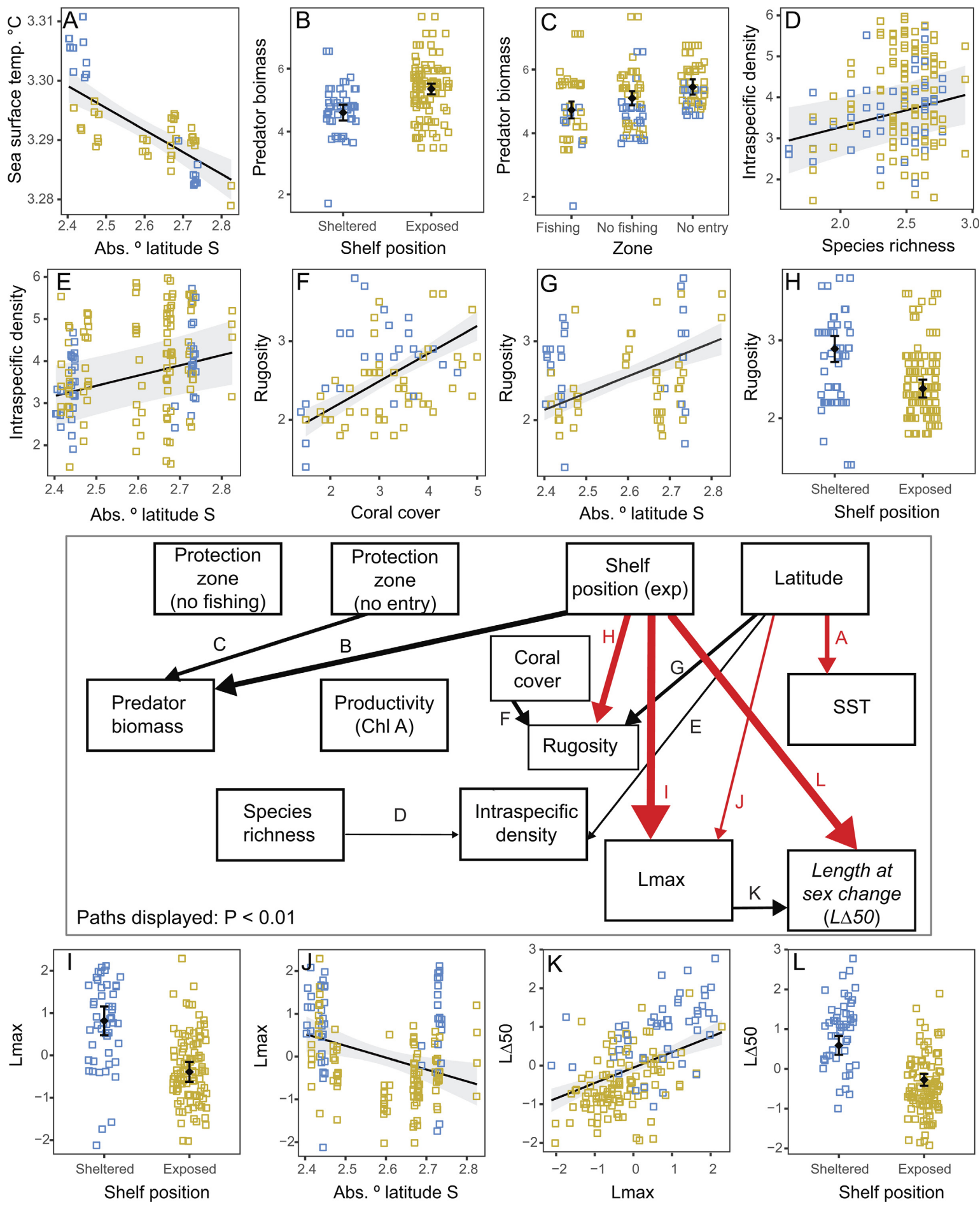

FIG. 2. Directed acyclic graph displaying standardized regression coefficients for highly significant $(P<0.01)$ hypothesized pathways. Solid black and red arrows represent pathways with positive and negative coefficients, respectively. Line thickness reflects coefficient values. Subplots (A-H) represent the effects plots for significant pathways between explanatory factors. Plots (I-L) represent effects plots for significant pathways to the primary response variables, maximum length and length at sex change. Additional effects plots are presented in Appendix S1: Fig. S2. 

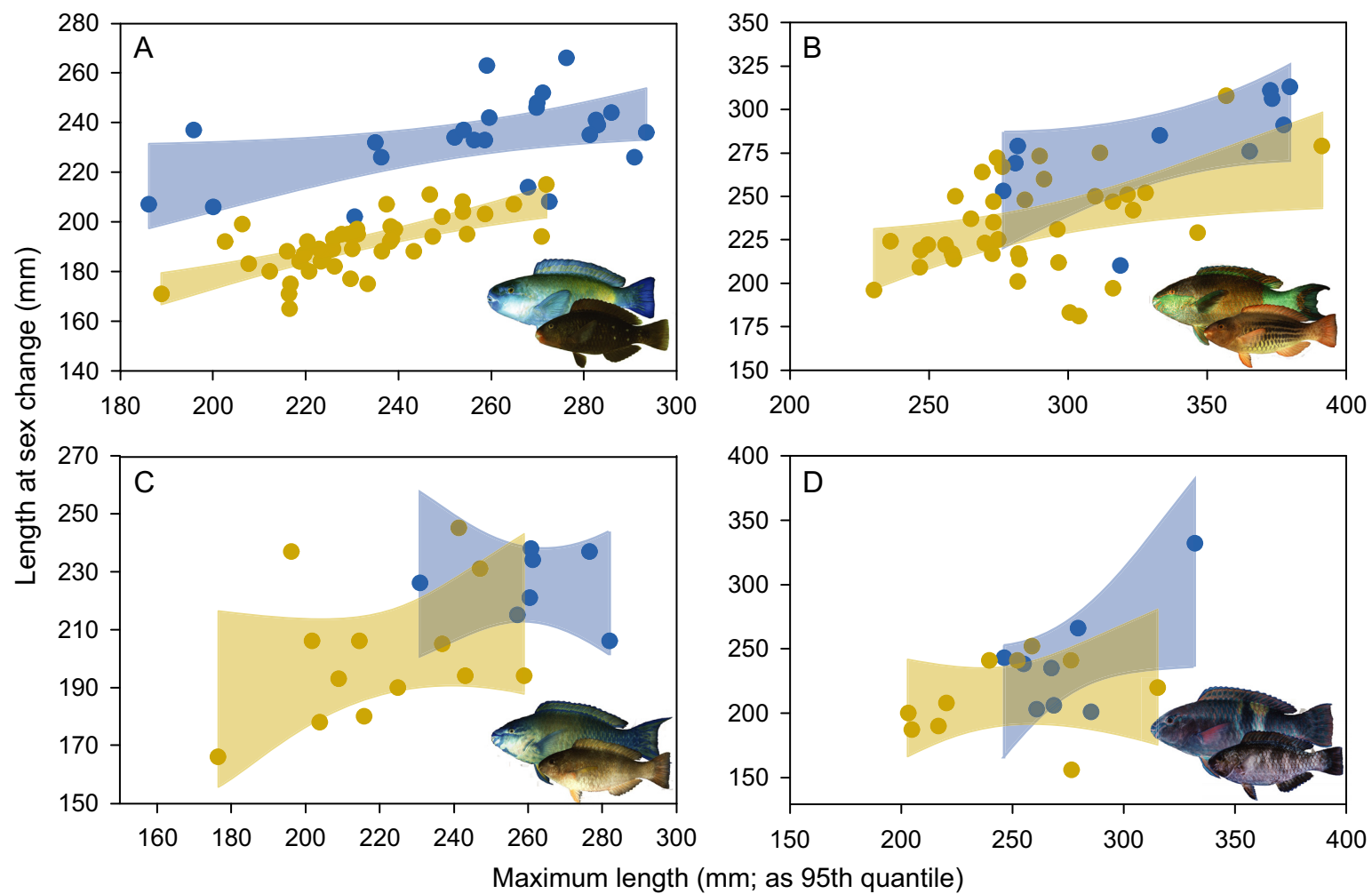

FIG. 3. Relationships between maximum length (represented here as the 95th quantile of the body size distribution) and length at sex change across sheltered mid and inner shelf reefs (blue) and exposed outer shelf reefs (yellow) of the Great Barrier Reef ( $n_{\max }=82$ sites) for four parrotfish species: (A) Chlorurus spilurus, (B) Scarus frenatus, (C) S. psittacus, and (D) S. schlegeli. Shaded regions represent $95 \%$ confidence limits surrounding linear regression fits to each exposure regime.

\section{Drivers of parrotfish size distributions}

Our results suggest that parrotfish body size distributions are weakly influenced by ambient temperature and productivity, but are highly influenced by biophysical features associated with shelf positions along the northern GBR. Temperature and productivity (estimates of food quality and availability) are strongly linked to metabolic processes in ectotherms (Atkinson 1994, Anguilleta et al. 2004). In contrast, underlying drivers of variation between exposed and sheltered reefs remain much less clear and, to date, have not been explicitly linked to changes in reef fish life-history traits. A major difference between these systems is the intensity of perpetual hydrodynamic forces that influence benthic structure (Done 1982). Parrotfishes are nutritionally reliant on benthic resources; specifically, they target endolithic and epilithic microbes, and, to a lesser extent, detrital material (Clements et al. 2017). There is evidence that the distribution and productivity of such nutritional resources varies along exposure gradients (Crossman et al. 2001, Tribollet and Golubic 2005, Tribollet 2008), with epilithic resources increasing in sheltered environments and endolithic resources increasing in exposed environments. This variation likely facilitates different growth rates and resultant size distributions of the consumers who differentially target both resources. Further refinement of productivity estimates beyond satellitederived Chl-A may strengthen the link between shelf position, benthic productivity, and body size distributions. Gust et al. (2002), while examining life-history traits of fishes from an overlapping subset of the reefs surveyed here, demonstrated a general pattern of faster initial growth leading to larger body sizes at sheltered mid shelf reefs for three parrotfishes (including C. spilurus and $S$. frenatus) and a surgeonfish. Further, higher adult mortality rates were linked to shorter life spans on the exposed outer shelf reefs.

The consistent shelf-related variability in body size and concomitant life-history traits observed by Gust et al. (2002) and Gust (2004) was attributed to differences in food levels, predation rates, and [intraspecific] competition, all of which contribute to mortality rates. We extended the scope across a greater diversity of environments spanning the northern half of the GBR, and, based on our holistic analytical framework, posit that, among these variables, resource distribution and quality across exposure gradients have by far the greatest effect, while the previously reported effects of predation and competition are likely by-products of the observed variation. 
Food availability is often a limiting factor in animal growth and has produced similar demographic differences in a variety of marine and terrestrial ectotherms (e.g., Clifton 1995, Hjelm et al. 2000, Madsen and Shine 2000), including reef fishes (Bonin et al. 2015), sometimes over small spatial scales. We found no relationship in our model between intraspecific density and body size distributions within or across shelf positions, suggesting that competition was not a major factor. We recognize that this analysis was not corrected for underlying resource levels and acknowledge that competition may be demographically important. However, our results suggest it is not the primary driver of the demographic variation observed. We also found no relationship between predator biomass and body size distributions. This result implies either (1) that variation in predation-induced mortality does not account for observed demographic variation or (2) that predator biomass may not be an appropriate indicator of predator-induced mortality in the study system. Greater adult mortality rates observed on exposed reefs (Gust et al. 2002) correspond with lifehistory theory predicting greater reproductive allocation associated with shorter life spans (Stearns 1976). It is not entirely clear whether the source of greater mortality on exposed shelves is extrinsic (e.g., predation) or intrinsic (i.e., linked to rate of metabolic processes; see Brown et al. 2004), but our results suggest the latter.

\section{The effect of size distributions and mating systems on length at sex change}

A defining feature of social control is that the length at sex change tends to be a function of the local size distribution (Warner 1984). This pattern was demonstrated in the present study, but for at least two species there was remarkable additional variation (after normalizing for underlying size distribution) associated with shelf position. This result suggests that changes in social demography associated with different environments elicits further control on sexual selection (Warner and Hoffman 1980). Gust (2004) found large differences in the proportion of initial phase primary males between mid and outer shelf populations of $C$. spilurus (i.e., more initial phase males at outer shelf reefs). This pattern strongly implies that haremic territoriality among males was the predominant mating system at sheltered mid shelf reefs where primary males were rare, and that group spawning emerged to some degree at exposed outer shelf reefs. Such changes in mating strategies can influence the size-related reproductive value of males (Warner 1984), and potentially explains the differences we observe after correcting for underlying body size distributions between exposure regimes. For example, conceptual application of the sizeadvantage hypothesis implies that, if male and female reproductive values are stable, the shifts in body size distribution observed between habitats would yield proportional shifts in $L_{\Delta 50}$ (orange arrow in Fig. 4A). However, if larger body size distributions select for greater prevalence of haremic territoriality, and haremic male reproductive values favor the largest males, then the optimal $L_{\Delta 50}$ would be higher than expected based on body size distributions alone (blue arrow in Fig. 4B) compared to a less haremic system. A related scenario was observed by Bruggemann et al. (1994) for Sparisoma viride (Bonaire, Caribbean) between depth zones. In that study, disparity in substrate densities led to different nutritional yields, which were linked to changes in mean body size and associated variability in mating systems. Deriving a better understanding of the mechanisms for how environmental features can affect mating systems is an important objective for future research.

\section{Linking ecosystem processes and demographic patterns across spatial scales}

Despite the influence of social factors described above, we found only weak evidence of consistent relationships among body size distributions, population density, and

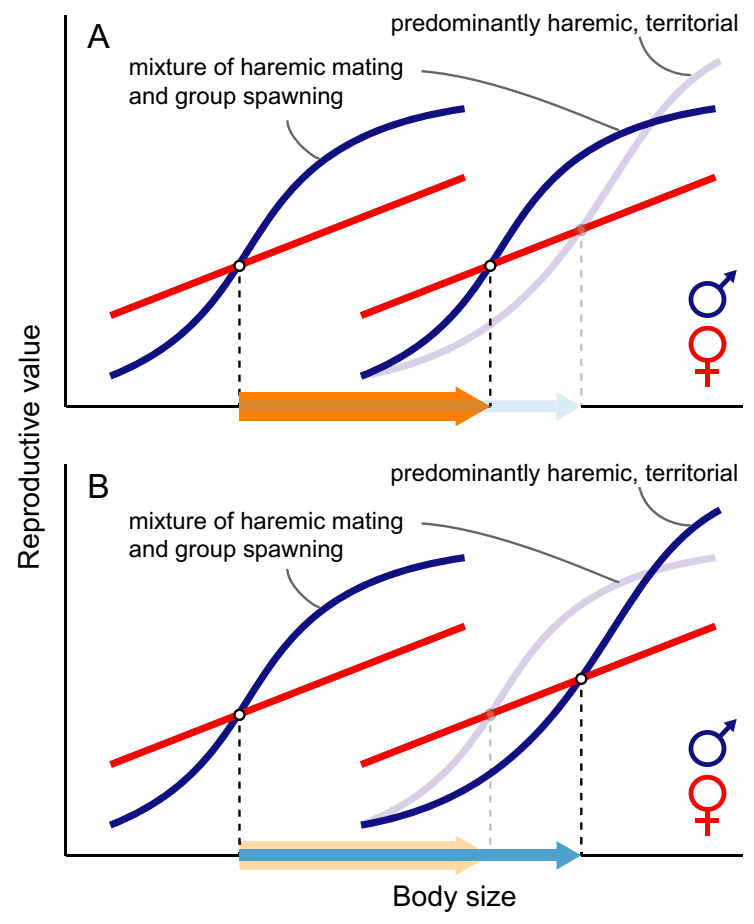

FIG. 4. Conceptual diagram depicting potential change in the optimal size at sex change $\left(L_{\Delta 50}\right.$ [dotted line]; intercept of male and female reproductive values following the size-advantage hypothesis) across populations with different body sizes and alternative mating systems. In (A), the orange arrow represents the expected change in $L_{\Delta 50}$ based only on proportional shifts in body size distribution, with mating system remaining unchanged. In (B), the blue arrow represents expected change in $L_{\Delta 50}$ based on shifts in body size distribution coupled with changes in the rate of male reproductive value as the prevalence of haremic territoriality changes. Note that reproductive value is an age-related value, but for parrotfishes with only moderately determinant growth, the curves presented across body size should be approximately correct. 
sex ratio across species (Appendix S1: Fig. S3). This result is somewhat in contrast with patterns for $C$. spilurus from Micronesia (using an identical survey strategy), where strong relationships among these three factors were discovered at spatial scales matching those of the present study (Taylor 2014). We reconcile these perceived differences based on the spatial distribution of the observed systems. In Micronesia, variability was measured within and among highly isolated island systems, where the influence of social structure was much easier to quantify in the absence of extreme habitat variability. In contrast, on the GBR social groups and subpopulations at close proximity reefs are subject to extremely high among-reef variability, thereby obscuring our ability to easily identify such relationships.

The major similarity among cosmopolitan species across both the northern GBR (present study) and oligotrophic islands of Micronesia (Taylor 2014) is that, at relatively large spatial scales $(>100-1,000 \mathrm{~km})$, geomorphological features appear highly influential of observed patterns of variation in length at sex change for dichromatic parrotfishes. The categorical distinction between shelf positions (GBR) and between island types (Micronesia) consistently explained the majority of the response variance despite considerable gradients of latitude (GBR) and fishery exploitation (Micronesia), suggesting that geomorphological features influence variation in demographic traits through their hierarchical effect on biotic factors directly affecting life-history variation. Although we were not able to determine mating systems at the site level across the scale of our study, prior biological sampling and decades of research on the dynamics of sex change suggest that the variation observed among distinct environments was driven by shelfassociated alternative mating systems. Broadening observations and analyses of life-history variation to mesoscales, as done here, is an important research objective. In particular, given the direct link between variation in life-history traits (such as growth rate) and ecosystemlevel parameters that indicate overall ecosystem functioning (such as secondary biomass production), identifying the hierarchy of underlying drivers of demographic variation represents a paramount objective in the study of coral-reef ecosystems.

Broad-scale investigations of life-history variation help identify the capacity of populations to achieve local adaptation, thereby linking ecological and evolutionary processes (Petersen and Warner 2002). This study and others have demonstrated the high magnitude of lifehistory variation across multiple spatial scales in sex changing reef fishes, as well as the hierarchical and context-specific nature of relationships between life-history traits and influential factors. We expect that environmental perturbations concomitant with climate change will have major impacts on the persistence of coral-reef fish species (Munday et al. 2008), and the ability to modify demographic profiles to optimize survivability will be critical to population persistence.

\section{ACKNOWLEDGMENTS}

This project was made possible by the Khaled Bin Sultan Living Oceans Foundation and was supported by a James Cook University Graduate Research grant to B.M.T. We thank P. Chops for gear maintenance and F. Carvalho, K. Clements, A. Heenan, B. Langseth, and J. O'Malley for helpful discussions. Comments by three anonymous reviewers greatly improved the framework and direction of the manuscript.

\section{Literature Cited}

Agrawal, A. A. 2001. Phenotypic plasticity in the interactions and evolution of species. Science 294:321-326.

Allsop, D. J., and S. A. West. 2003. Life history: Changing sex at the same relative body size. Nature 425:783-784.

Anguilleta, M. J., T. D. Steury, and M. W. Sears. 2004. Temperature, growth rate, and body size in ectotherms: fitting pieces of a life-history puzzle. Integrative and Comparative Biology 44:498-509.

Atkinson, D. 1994. Temperature and organism size - a biological law for ectotherms? Advances in Ecological Research 25:1-58.

Bonin, M. C., L. Boström-Einarsson, P. L. Munday, and G. P. Jones. 2015. The prevalence and importance of competition among coral reef fishes. Annual Review of Ecology, Evolution, and Systematics 46:169-190.

Bradshaw, A. D. 1965. Evolutionary significance of phenotypic plasticity in plants. Advances in Genetics 13:115-155.

Brodie, J., G. De'ath, M. Delvin, M. Furnas, and M. Wright. 2007. Spatial and temporal patterns of near-surface chlorophyll $a$ in the Great Barrier Reef lagoon. Marine and Freshwater Research 58:342-353.

Brown, J. H., J. F. Gillooly, A. P. Allen, V. M. Savage, and G. B. West. 2004. Toward a metabolic theory of ecology. Ecology 85:1771-1789.

Bruggemann, J. H., M. J. H. van Oppen, and A. M. Breeman. 1994. Foraging by the stoplight parrotfish Sparisoma viride. I. Food selection in different, socially determined habitats. Marine Ecology Progress Series 106:41-55.

Charnov, E. L. 1982. The theory of sex allocation. Princeton University Press, Princeton, New Jersey, USA.

Clements, K. D., D. P. German, J. Piché, A. Tribollet, and J. H. Choat. 2017. Integrating ecological roles and trophic diversification on coral reefs: multiple lines of evidence identify parrotfishes as microphages. Biological Journal of the Linnean Society 120:729-751.

Clifton, K. E. 1995. Asynchronous food availability on neighbouring Caribbean coral reefs determines seasonal patterns of growth and reproduction for the herbivorous parrotfish Scarus iserti. Marine Ecology Progress Series 116:39-46.

Crossman, D. J., J. H. Choat, K. D. Clements, T. Hardy, and J. McConochie. 2001. Detritus as food for grazing fishes on coral reefs. Limnology and Oceanography 46:1596-1605.

DeMartini, E. E., A. M. Friedlander, and S. R. Holzwarth. 2005. Size at sex change in protogynous labroids, prey body size distributions, and apex predator densities at NW Hawaiian atolls. Marine Ecology Progress Series 297:259-271.

DeMartini, E. E., A. M. Friedlander, S. A. Sandin, and E. Sala. 2008. Differences in fish-assemblage structure between fished and unfished atolls in the northern Line Islands, central Pacific. Marine Ecology Progress Series 365:199-215.

Done, T. J. 1982. Patterns in the distribution of coral communities across the central Great Barrier Reef. Coral Reefs 1:95-107.

Fagen, R. 1987. Phenotypic plasticity and social environment. Evolutionary Ecology 1:263-271.

Gardner, A., D. J. Allsop, E. L. Charnov, and S. A. West. 2005. A dimensionless invariant for relative size at sex change in 
animals: explanation and implications. American Naturalist 165:551-566.

Ghiselin, M. T. 1969. The evolution of hermaphroditism among animals. Quarterly Review of Biology 44:189-208.

Gove, J. M., G. J. Williams, M. A. McManus, S. F. Heron, S. A. Sandin, O. J. Vetter, and D. G. Foley. 2013. Quantifying climatological ranges and anomalies for Pacific coral reef ecosystems. PLoS ONE 8:e61974.

Gust, N. 2004. Variation in the population biology of protogynous coral reef fishes over tens of kilometers. Canadian Journal of Fisheries and Aquatic Science 61:205-218.

Gust, N., J. H. Choat, and J. L. Ackerman. 2002. Demographic plasticity in tropical reef fishes. Marine Biology 140 1039-1051.

Haddon, M. 2001. Modelling and quantitative methods in fisheries. Chapman and Hall, New York, New York, USA.

Hall, A. E., and M. J. Kingsford. 2016. Variation in the population demographics of Scolopsis bilineatus in response to predators. Coral Reefs 35:1173-1185

Henson, S. A., and R. R. Warner. 1997. Male and female alternative reproductive beahviors in fishes: a new approach using intersexual dynamics. Annual Review of Ecology and Systematics 28:571-592.

Hjelm, J., L. Persson, and B. Christensen. 2000. Growth, morphological variation and ontogenetic niche shifts in perch (Perca fluviatilis) in relation to resource availability. Oecologica 122:190-199.

Hutchings, J. A. 2011. Old wine in new bottles: reaction norms in salmonid fishes. Heredity 106:421-437.

Kilpatrick, K. A., G. Podesta, S. Walsh, E. Williams, V. Halliwell, M. Szczodrak, O. B. Brown, P. J. Minnett, and R. Evans. 2015. A decade of sea surface temperature from MODIS. Remote Sensing of Environment 165:27-41.

Lefcheck, J. S. 2015. PiecewiseSEM: piecewise structural equation modeling in $\mathrm{R}$ for ecology, evolution, and systematics. Methods in Ecology and Evolution 7:573-579.

Madsen, T., and R. Shine. 2000. Silver spoons and snake body sizes: prey availability early in life influences long-term growth rates of free-ranging pythons. Journal of Animal Ecology 69:952-958.

Mora, C. 2015. Ecology of fishes on coral reefs. Cambridge University Press, Cambridge, UK.

Munday, P. L., P. M. Buston, and R. R. Warner. 2006. Diversity and flexibility of sex-change strategies in animals. Trends in Ecology and Evolution 21:89-95.

Munday, P. L., G. P. Jones, M. S. Pratchett, and A. J. Williams. 2008. Climate change and the future for coral reef fishes. Fish and Fisheries 9:261-285.

Petersen, C. W., and R. R. Warner. 2002. The ecological context of reproductive behavior. Pages 103-118 in P. F. Sale, editor. Coral reef fishes: dynamics and diversity in a complex ecosystem. Academic Press, San Diego, California, USA.
Robertson, D. R., J. L. Ackerman, J. H. Choat, J. M. Posada, and J. Pitt. 2005. Ocean surgeonfish Acanthurus bahianus. I. The geography of demography. Marine Ecology Progress Series 295:229-244.

Ross, R. M. 1990. The evolution of sex-change mechanisms in fishes. Environmental Biology of Fishes 29:81-93.

Ruttenberg, B. I., A. J. Haupt, A. I. Chiriboga, and R. R. Warner. 2005. Patterns, causes and consequences of regional variation in the ecology and life history of a reef fish. Oecologia 145:394-403.

Sale, P. F. 2002. Coral reef fishes: dynamics and diversity in a complex ecosystem. Academic Press, San Diego, California, USA.

Schaffer, W. M. 2004. Life histories, evolution, and salmonids Pages $20-51$ in A. P. Hendry and S. C. Stearns, editors. Evolution illuminated: salmon and their relatives. Oxford University Press, New York, New York, USA.

Schlichting, C. D., and M. Pigliucci. 1998. Phenotypic evolution: a reaction norm perspective. Sinauer Associates, Sunderland, Massachusetts, USA.

Schmalhausen, I. I. 1949. Factors of evolution. Blakiston, Philadelphia, Pennsylvania, USA.

Shapiro, D. Y. 1991. Intraspecific variability in social systems of coral reef fishes. Pages 331-355 in P. F. Sale, editor. The ecology of fishes on coral reefs. Academic Press, San Diego, California, USA

Shipley, B. 2009. Confirmatory pathway analysis in a generalized multilevel context. Ecology 90:363-368.

Stearns, S. C. 1976. Life-history tactics: a review of the ideas. Quarterly Review of Biology 51:3-47.

Taylor, B. M. 2014. Drivers of protogynous sex change differ across spatial scales. Proceedings of the Royal Society B: Biological Sciences 281:20132423.

Tribollet, A. 2008. Dissolution of dead corals by euendolithic microorganisms across the northern Great Barrier Reef (Australia). Microbial Ecology 55:569-580.

Tribollet, A., and S. Golubic. 2005. Cross-shelf differences in the pattern and pace of bioerosion of experimental carbonate substrates exposed for 3 years on the northern Great Barrier Reef, Australia. Coral Reefs 24:422-434.

Warner, R. R. 1975. The adaptive significance of sequential hermaphroditism in animals. American Naturalist 109:61-82.

Warner, R. R. 1984. Mating behavior and hermaphroditism in coral reef fishes. American Scientist 72:128-136.

Warner, R. R. 1991. The use of phenotypic plasticity in coral reef fishes as tests of theory in evolutionary ecology. Pages 387-398 in P. F. Sale, editor. The ecology of fishes on coral reefs. Academic Press, San Diego, California, USA.

Warner, R. R., and S. G. Hoffman. 1980. Local population size as a determinant of mating system and sexual composition in two tropical marine fishes (Thalassoma spp). Evolution 34: 508-518.

\section{SUPPORTING INFORMATION}

Additional supporting information may be found in the online version of this article at http://onlinelibrary.wiley.com/doi/ 10.1002/ecy.2127/suppinfo 